\title{
Lunar Dome - Tent for the Apollo 11 roadshow
}

\author{
Bernd Stimpfle* \\ * formTL ingenieure für tragwerk und leichtbau $\mathrm{GmbH}$ \\ Güttinger Str. 37, 78315 Radolfzell, Germany \\ e-mail: info@form-tl.de, http://www.form-tl.de
}

\begin{abstract}
In the year 1969 Apollo 11 brought the first humans to the moon. On the occasion of the 50th anniversary a big roadshow was designed which should travel through several cities of the United States of America. A huge theatre tent with 1600 seats was developed. As temporary building the tent consists of single elements which are optimized for a fast assembly and an easy transportation.

An arch-supported main membrane, an elastically supported projection dome and a huge ETFE façade form the different envelopes and reduce the tent character of the project. Adaptable base elements, anchored with long pegs, are used as flexible foundation for the different locations. In summer 2019 the temporary theatre for "Apollo 11 - the immersive live show" was in Pasadena.

Four steel trussed arches form the supporting structure. All four arches consist of rectangular framework elements connected together with bolts. Steel cables link the whole structure in order to keep the arches in position. Steel ridge cables are integrated into the membrane under the arches They transfer the membrane loads into the steel structure and serve as field joint.

The paper is about the structural design of the main structure and the integration of the secondary elements for the projection membrane and the entrance façade. It describes the design process, from the formfinding process to the structural analysis, the cutting pattern generation and the installation process.
\end{abstract}

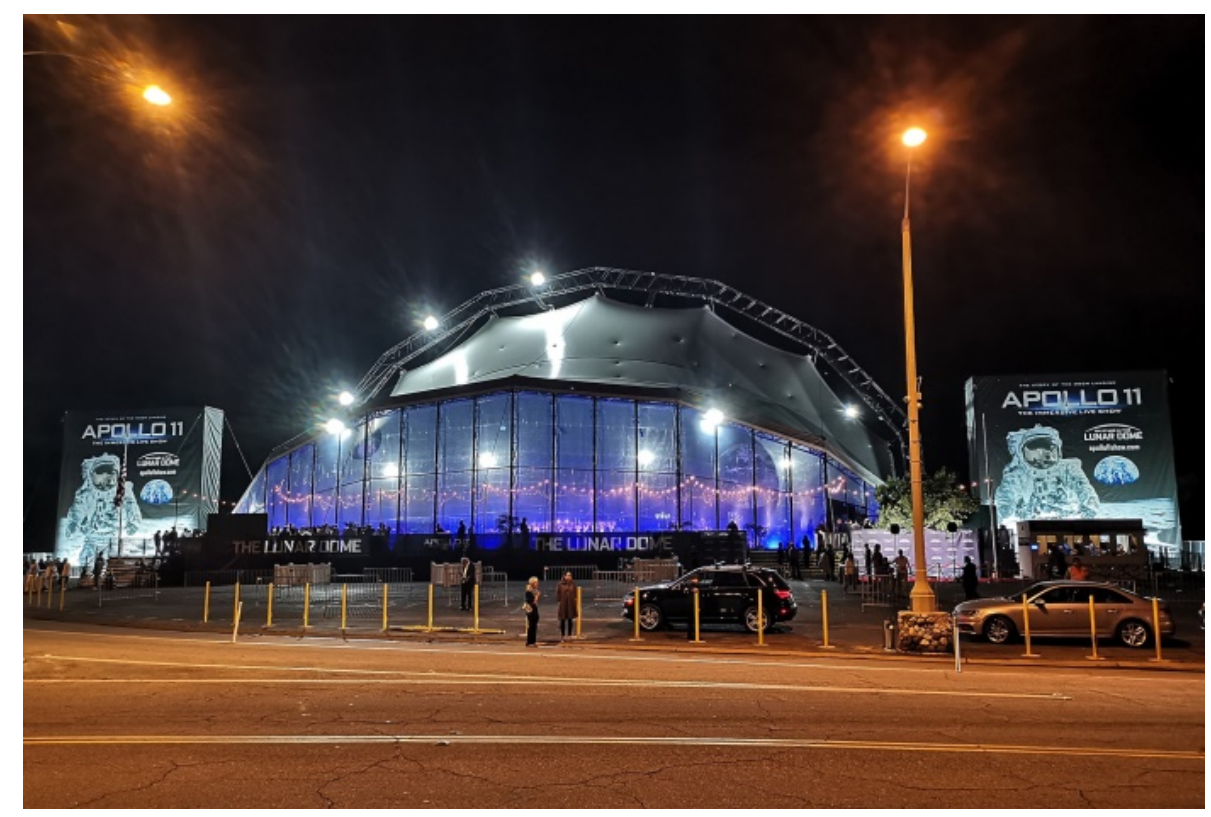

Picture: Matthew Churchill Production Ltd

\section{REFERENCES}

[1] Stahlbau 89 (2020), Zelt für die Apollo 11 Roadshow in den USA 